\title{
Trilateral retinoblastoma in Sub-Saharan Africa: problem of diagnosis and medical management
}

\author{
Ibrahim Abib Diomandé1, Ahgbatouhabéba Ahnoux-Zabsonré2 ${ }^{2}$ Windinmanégdé Pierre Djiguimdé ${ }^{2}$, Abdoulaye Toure*3, \\ Konan Virgile Koffi ${ }^{1}$, Pepin Williams Atipo-Tsiba ${ }^{4}$, Philippe Koffi France Emile Bile ${ }^{1}$, Gosse François Diomandé ${ }^{1}$ \\ ${ }^{1}$ Ophthalmology Department, Center Hospital University, Bouaké, Côte-d'Ivoire \\ ${ }^{2}$ Ophthalmology Department, Center Hospital University, Yalgado Ouedraogo, Ouagadougou, Burkina Faso \\ ${ }^{3}$ Radiology Department, University Hospital of Yopougon, University Felix HouphouetBoigny, Côte-d'Ivoire \\ ${ }^{4}$ Department of Ophthalmology, University Hospital of Brazzaville, Brazzaville, Congo
}

Received: December 11, 2015

DOI: $10.5430 /$ crcp.v3n2p4
Accepted: January 31, $2016 \quad$ Online Published: February 20, 2016

URL: http://dx.doi.org/10.5430/crcp.v3n2p4

\begin{abstract}
Trilateral retinoblastoma (TRB) is a syndrome consisting of unilateral or bilateral hereditary retinoblastoma (RB) associated with an intracranial neuroblastic tumor. It is an eye-brain disease uncommon combination of eye and brain clinical manifestations. Its diagnosis and its treatment are a problem in developing countries. We report the case of a TRB supported by a literature review.
\end{abstract}

Key Words: Retinoblastoma, Pinéoblastoma, Pediatrics, Imaging, Treatment, Prognosis

\section{INTRODUCTION}

Trilateral retinoblastoma (TRB) or ectopic retinoblastoma (RB) is a malignant tumor developed at the expense of young cells of the retina and the pineal or epiphysis region. This is a rare disease estimated to 1 case out of 34,000 births. ${ }^{[1]}$ Symptoms concern both organs: eye and brain. The outcome remains fatal part from a management involves several practicians: ophthalmologists, neurosurgeons, oncologists and radiologists. Through a case of TRB supported by the literature, we bring out specific nature of this disease, the difficulties of diagnosis and its treatment in our developing countries.

\section{Case presentation}

A 3-year-old female was seen for left exophthalmia started six months ago without any specific history. Symptoms began with repeated headaches, itching and watery eyes; lead- ing parents to set an appointment with a traditional healer. The given treatments based on plant infusions has been unsuccessfully for 3 months. The Occurrence of leukocoria with exacerbated exophthalmia and other symptoms quoted above, patient was taken to the neighboring rural health center which referral to our specialized service for better medical care. Up on examination the left eye is fully blind with protrusion of a mass roughly rounded through the lid slot (see Figure 1A). It appears enlarged in it transverse diameter and measured $60 \mathrm{~cm}$, immobile and deflected toward the nasal side. The surface was burgeoning, Hemorrhagic vessels are clearly identified a necrotic corneal remaining. The other structures of the anterior segment, and the posterior segment, were not appreciable. The mass was non-reducible, hot, throbbing and painful while slightly depressed. The visual acuity of the right eye was reduced to light perception. The anterior segment was normal. A yellowish white endophytic

\footnotetext{
*Correspondence: Abdoulaye Toure; Email: tourreadam@ yahoo.fr; Address: Radiology Department, University Hospital of Yopougon, University Felix HouphouetBoigny, Cote d'Ivoire.
} 
mass that raised the retina was seen in the posterior segment. Elsewhere, a bulge is identified on the forehead and a tender and painful lymphadenopathy beside the left ear. The chest physical exam was unremarkable: the bony thoracic cage, the heart and lungs have been cleared with no findings. The abdomen, the urinary tract and the extremities were cleared with the abnormality.

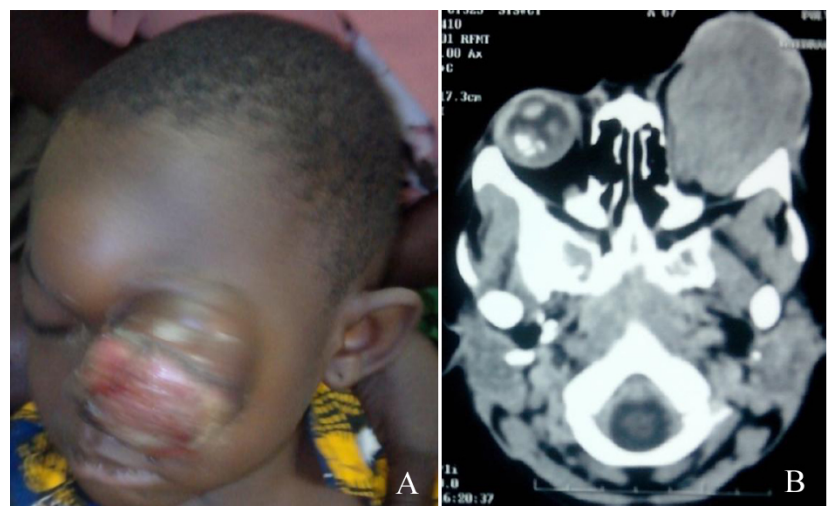

Figure 1. A: Protrusion of a mass roughly rounded through the lid slot. This mass is immobile and deflected towards nasal side. Its surface was burgeoning, vascularized and bleeding; B: Cerebro-ocular axial section CT scan objectiving tumor mass filling the entire orbital content in the left eye and intraocular calcifications that were presented in hyperdense mass forms.

The patient had no past medical story of RB in a family. The medical investigation was delay because of economic matters. Parents couldn't effort the medical expenses. One of the most helpful exams: the orbital/brain CT scan was performed with two weeks delay. He has been barely possible after help received from the hospital's social services. This CT scan revealed a tumor mass filling the entire orbital content in the left eye (see Figure 1B). It also identified a dual tumor mass in which the first was straddling and destroying the bone underneath the forehead. The second was supra sellar, bilobed with compression of the third ventricle (see Figure 2). In the right eye the CT scan revealed intra ocular calcification appearing like a high density mass. The diagnosis of TRB was retained based on anamnestic, clinical and paraclinical (imaging) arguments. The evolution was marked by the death of the patient before any treatment after diagnosis of TRB because parents had a low income and couldn't bear the burden of the medical needs.

\section{Ethics statement}

This case report followed the tenets of the Declaration of Helsinki and was approved by the Center Hospital University of Bouaké. Consent was obtained from the child's parents.

\section{Discussion}

TRB was described for the first time in 1971 by Jensen et $a .^{[2]}$ This is a rare condition as underlined by another authors. ${ }^{[3,4]}$ In the eye tumors registry of ophthalmology department to the Center Hospital University of Bouake (Côted'Ivoire), we have noticed the only one case of TRB on a total of $75 \mathrm{RB}$ standing for a prevalence of $1.33 \%$. African literature notes few studies about TRB. Nikema and col (4) in 2009 found 3 cases of TRB in Burkina Faso on a total of $23 \mathrm{RB}$ corresponding to a frequency of $13 \%$. Although TRB has uncommon pathology, many researches have provided interesting results in Western countries. From 1985 to 2004 we noted different frequency of TRB between $0.6 \%$ to $12.7 \%$ according to countries. ${ }^{[5]}$ Our patient was a female. Literature reviews indicated a majority of TRB among female $52 \%$ to $53 \%$ of cases The detection average age of the TRB would be between 26 months and 30.7 months. ${ }^{[5,6]}$ Our patient's age ( 3 years) is concordant if we pay attention to the delay of consultation and diagnosis in sub-Saharan Africa countries. Indeed the majority of black african people, especially those who are living in rural areas, try first a traditional treatment causing the delay of appropriate medical care. ${ }^{[7]}$ Other parameters such as poverty of the population, and the lack of universal health insurance deny access to health care centers. People are unable to effort the expenses. The lake of health structures sometimes under equipped are also ostacles to early consultation and medical care of patients in our countries. ${ }^{[8]}$ According to these facts we easily understand that and exophtalmia could be in relationship with advanced stage of RB. It has been proved that the photoreceptors of the pineal glands is similarity to those of the retina in some species explaining the close relationship between $\mathrm{RB}$ and pinealoblastoma. ${ }^{[9,10]}$ Cerebral manifestation of $\mathrm{RB}$ is more common in case of bilateral ocular involvement (86\% to $89 \%$ ) as observed through many studies. ${ }^{[1]}$ The likelihood of brain damage of our patient was so high because of a bilateral RB. According to the literature, there would exist a lag time between the ocular RB and brain dissemination which would be about 24.6 months. ${ }^{[12]}$ Our realities of medical practice related to socio-economic contexts do not allow to appreciate this latency for our patients who are seen generally at a late stage of the disease. The cerebral localizations of RB are observed on sellar or pineal gland. The sellar is reached earlier but the pineal tumor location would be more frequent. The story of the disease for our patient led to the discovery of leukocoria, preceded the onset of orbital swelling exophthalmia. Also she had further severe headache which may be associated with brain damage. Conventionally, the TRB would present ocular signs related to RB itself mainly leukocoria and strabismus. ${ }^{[13]}$ Brain manifestations 
are diverse. Headaches are the main symptom unanimously described in the litterature. ${ }^{[14]}$ They may be associated with nausea, vomiting, macrocrania and seizure attacks. However some patients would not present extra ocular signs. ${ }^{[15,16]}$ The brain tumor can be discovered surprisingly during routine CT scan explorations in the radiological assessment of RB 8 like for our patient whose CT scan was possible only after the intervention of social services. ${ }^{[12]}$ Imaging (CT and MRI) arguments confirms the diagnosis by highlighting the mass and calcifications in intraocular reliable to the RB. It also shows the presence of intracerebral mass which has a several locations. Some studies performed about TRB showed "Flexner winter Steiner rosettes" cells and undifferentiated tumorsin majority look like primitive neuroectodermal tumors (PNET) after histopathology brain tumors' analysis. ${ }^{[17]}$ Indeed, the poverty of the population, the scarcity of health infrastructures and the deficiency of technical platforms sometimes make difficult to the definitive diagnosis. This reality helps us to understand that cases of TRB could be ignored fault of imaging realization several patients. The death of our patient untreated was predictable because the prognosis of the TRB is generally unfavorable, leadingto the death that occurs approximately within 1.3 months in untreated patients and 11.2 months in those who were treated according to the literature. It depends also of the size of the brain tumor ${ }^{[7]}$ These results are witnesses to the severity of this disease with mortality that occurs within 1 year even with a treatment. TRB prognosis also depends on the size of the brain tumor. More than $15 \mathrm{~mm}$ size would be a poor prognosis with a risk of leptomeningeal dissemination. The standard protocol treatment of TRB is total resection of the supra sellar mass after subtotal craniotomy followed by chemotherapy and brain irradiation. Most brain tumors are pineal type (PNET) and sensitive to the chemotherapy treatments. New protocols based on aggressive treatment combining conventional chemotherapy with high dose chemotherapy and hematopoietic stem cell reperfusion would lead to recovery of some patients. ${ }^{[18]}$ Most commonly used are vincristine, cyclophosphamide, ifosfamide, carboplatin, and etoposide. [19] Superselective ophthalmic artery chemotherapy (SOAC) with "Melphalan" or new local administration strategies such as periocular chemotherapy with "Topotecan" are recently been proposed as an alternative to intravenous chemoreduction for advanced intraocular RB but SOAC is associated with potentially sight-threatening adverse effects, such as severe chorioretinal atrophy secondary to subacute choroidal occlusive vasculopathy or central retinal artery embolism and the risk of ophthalmic artery obstruction. ${ }^{[20,21]}$ Munier's ${ }^{[22]}$ new interventional oncology treatment combined anti-reflux injection at a cryocoagulation the crossing point of the needle at $-70^{\circ}$. This technic destroys cancer cells that may have been driven out of the eye during removal of the needle.

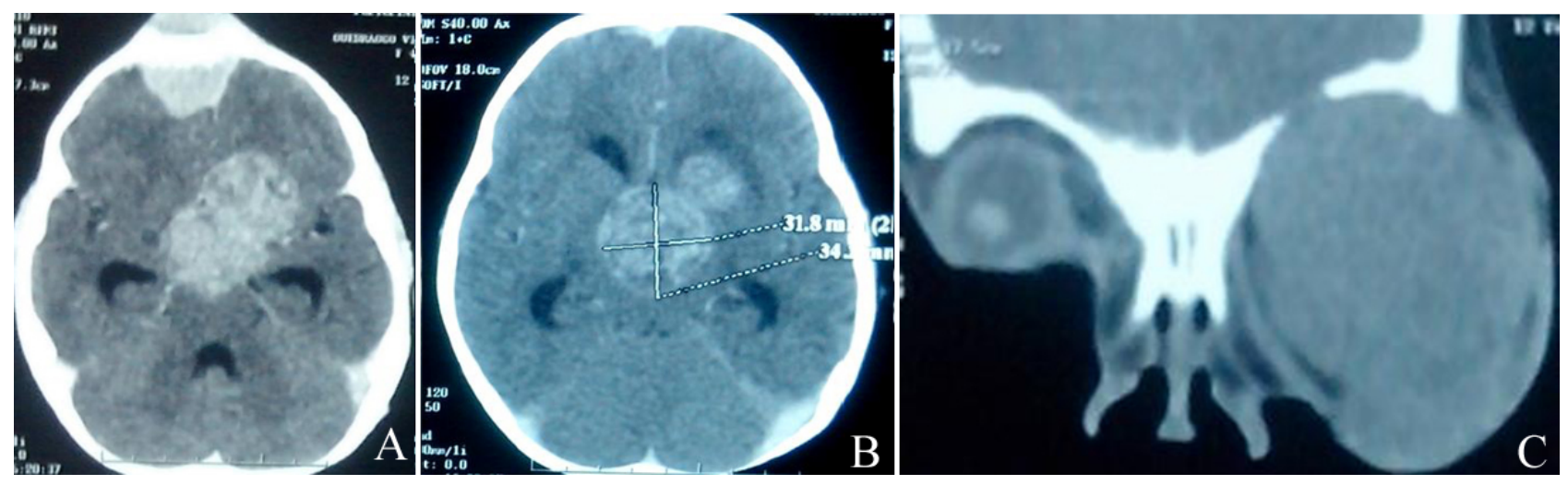

Figure 2. A and B: The cerebro-ocular CT scan axial parenchymal window shows a suprasellar mass bilobed with compression of the third ventricle; $\mathrm{C}$ : coronal bone section window shows a mass straddling the frontal bone with lysis thereof.

\section{Conclusion}

TRB is a serious rare disease but responsible of high mortality among children carrying RB especially in our developing countries in Sub-Saharan Africa. Although a recent study suggests that intensive chemotherapy may improve survival. Early detection is likely an important factor in survival. Monitoring with brain MR examinations at 6- to 12-month intervals may be of benefit to this group of patients with intracranial malignant neoplasms. For us, the improvement of living conditions and our health policy in Africa would facilitate early diagnosis and medical management to change its prognosis.

\section{Conflicts OF InTEREST Disclosure}

The authors report no conflicts of interest in this work. 


\section{REFERENCES}

[1] Ravindranath J. An increased relative frequency of retinoblastoma at a rural regional referral hospital in Miraj, Maharashtra, India. Cancer. 1993; 72: 282-6. http://dx.doi.org/10.1002/1097-0142(19 930701) 72: 1<282: :AID-CNCR2820720149>3 . 0.CO;2-A

[2] Jensen RD, Miller RW. Retinoblastoma: Epidemiologic characteristics. N Engl J Med. 1971; 285: 307-11. PMid: 5283015. http://dx.doi.org/10.1056/NEJM197108052850602

[3] Azar D, Donaldson C, Dalla-Pozza L. Questioning the need for routine bone marrow aspiration and lumbar puncture in patients with retinoblastoma. Clin Experiment Ophthalmol. 2003; 31: 57-60. PMid: 12580896. http://dx.doi.org/10.1046/j.1442-9071. 2003.00601.x

[4] Nikiema Z, Diallo JW, Daboue A. Trilateral retinoblastoma in Burkina Faso: three cases. Cahiers Santé. 2009; 19: 185-8. PMid: 20199945.

[5] Mouratova T. Retinoblastoma in Uzbekistan. Bull SocbelgeOphtalmol. 2003; 289: 63-9. PMid: 14619631.

[6] Provenzale JM, Gururangan S, Klintworth G. Trilateral retinoblastoma: clinical and radiologic progression. AJR Am J Roentgenol. 2004; 183: 505-11. PMid: 15269048. http://dx.doi.org/10. 22 14/ajr.183.2.1830505

[7] Garaffini T, Toussain P, Milazzo S, et al. Proptosis and orbital tumors: A retrospective study during 15 years. Ophtalmologie. 1997; 11(1): 1-5.

[8] Doumbouya ML. Accessibility of health services in West Africa: case of the Guin'ee. Working paper. 2008. <Halshs-00229696>

[9] Bader JL, Meadows AT, Zimmerman LE, et al. Bilateral retinoblastoma with ectopic intracranial retinoblastoma: trilateral retinoblastoma. Cancer Genet Cytogenet. 1982; 5: 203-13. http://dx.doi . org/10.1016/0165-4608(82) 90026-7

[10] Rodjan F, Degraaf P, Brisse HJ, et al. Trilateral retinoblastoma: neuroimaging characteristics and value of routine brain screening on admission. J Neuro oncol. 2012; 109: 535-44. PMid: 22802019. http://dx.doi.org/10.1007/s11060-012-0922-4

[11] Pesin SR, Shields JA. Seven cases of trilateral retinoblastoma. Am J Ophthalmol. 1989; 107: 121-6. http://dx.doi.org/10.1016/0 002-9394 (89) 90209-2

[12] Marcus DM, Brooks SE, Leff G, et al. Trilateral retinoblastoma: insights into histogenesis and management. Surv Ophthalmol. 1998; 43 :
59-70. http://dx.doi.org/10.1016/S0039-6257(98)00019 $-8$

[13] Skulski M, Egelhoff JC, Kollias S, et al. Trilateral retinoblastoma with suprasellar involvement. Neuroradiology. 1997; 39: 41-3. PMid: 9121647. http://dx.doi.org/10.1007/s002340050364

[14] Jubran RF, Erdreich-Epstein A, et al. Approaches to treatment for extraocular retinoblastoma.Children's Hospital Los Angeles experience. J Pediatr Hematol Oncol. 2004; 26: 31-4. PMid: 14707710. http://dx .doi .org/10.1097/00043426-200401000-00011

[15] Bagley LJ, Hurst RW, Zimmerman RA, et al. Imaging in the trilateral retinoblastoma syndrome. Neuroradiology. 1996; 38: 166-70. PMid: 8692433. http://dx.doi.org/10.1007/BF00604810

[16] Bejjani GK, Donahue DJ, Selby D, et al. Association of a suprasellar mass and intraocular retinoblastoma: a variant of pineal trilateral retinoblastoma. Pediatr Neurosurg. 1996; 25: 265-75. http: //dx.doi.org/10.1159/000121138

[17] Choe Y, Suh YL, Shin HJ. Trilateral retinoblasma: a case report. J Korean Med Sci. 2002; 17: 137-40. PMid: 11850605. http://dx.doi.org/10.3346/jkms.2002.17.1.137

[18] Dunkel IJ, Jubran RF, Gururangan S, et al. Trilateral retinoblastoma: Potentially curable with intensive chemotherapy. Pediatr Blood Cancer. 2010; 54: 384-7. PMid: 19908299. http://dx.doi.org/10. $1002 / \mathrm{pbc} .22336$

[19] Matsubara H, Makimoto A, Higa T, et al. A multidisciplinary treatment strategy that includes high-dose chemotherapy for metastatic retinoblastoma without CNS involvement. Bone Marrow Transplantation. 2005; 35: 763-6. PMid: 15750608. http://dx.doi.org/1 $0.1038 / \mathrm{sj}$. bmt . 1704882

[20] Munier FL, Beck-Popovic M, Balmer A, et al. Occurrence of sectoral choroidal occlusive vasculopathy and retinal arteriolar embolization after superselective ophthalmic artery chemotherapy for advanced intraocular retinoblastoma. Retina. 2011; 31: 566-73. PMid: 21273941. http://dx.doi.org/10.1097/IAE.0b013e318203c101

[21] Gobin YP, Dunkel IJ, Marr BP, et al. Intra-arterial chemotherapy for the management of retinoblastoma: Four-year experience. Arch. 2011; 129: 732-7. http://dx.doi.org/10.1001/archophthal $\operatorname{mol} .2011 .5$

[22] Munier FL, Soliman S, Moulin A, et al. Profiling safety of intravitreal injections for retinoblastoma using an anti-reflux procedure and sterilization of the needle track. British Journal of Ophthalmology. http://dx.doi.org/10.1136/bjophthalmol-2011-301016 